\title{
Psicologia, marketing e experiência elementar: implicações para o desenvolvimento do conceito de consumidor $^{\prime}$
}

\author{
Carmen Silvia Porto Brunialti Justo \\ Marina Massimi
}

\section{Introdução}

$\mathrm{P}$ or se tratar de uma ciência multidisciplinar, a área de marketing, desde seu surgimento a partir da Revolução Industrial (1780) e do avanço da economia nos Estados Unidos, no final do século XVIII, recebeu contribuições significativas dos estudos científicos da psicologia e, de diferentes áreas como: a sociologia, a economia e a história. Em especial, a psicologia, contribuiu de forma significativa, e psicólogos adeptos de diferentes teorias psicológicas se aproximaram da área com o objetivo de aplicar seus conhecimentos nos estudos sobre memória, reforço, análise do comportamento e motivações.

Nesse contexto, as investigações sobre o comportamento do consumidor, que até à década de 1950 não eram reconhecidas como área específica de pesquisa e de trabalho pela APA - American Psychology Association - passaram a ganhar reconhecimento a partir da década de 1960, com o surgimento da Divisão 23 (Divisão de psicologia do consumidor), legitimando a área como sendo de pesquisa em comportamento do consumidor no contexto dos estudos psicológicos (Justo e Massimi, 2014: 32).

Ao longo de diferentes momentos históricos do século XX o conceito de consumidor foi abordado estrategicamente, de acordo com o contexto histórico, social e político vigente. No início do século, com o avanço fabril, devido à baixa concorrência entre as empresas que começavam a surgir, as ações de marketing deveriam trabalhar 
a atenção, retenção e memória dos produtos no ponto de venda, para que pudessem influenciar a decisão de compra dos consumidores. Posteriormente, no final dos anos 1960, o consumidor tornou-se mais crítico com relação ao consumo de produtos. As abordagens mercadológicas passaram a focar na avaliação do comportamento psicológico do consumidor no ponto de venda, sobre o uso de cores nas embalagens e índices de audiência nos diferentes veículos de comunicação.

No final da década de 1980 e início das décadas de 1990 e 2000, observaram-se o surgimento de novas perspectivas do marketing. Entre outras, destacaram-se: o marketing de relacionamento (Reichheld, 2001: 100-104), o cybermarketing (Kotler; Kartajaya e Setiawan, 2010: 9-12), o marketing social/ambiental (Tenório, 2004: 1432) e o marketing experimental (Schmitt, 2002: 48-72), que passaram a enfatizar o papel do consumidor nas relações de mercado, estando seus estudos focados na sua participação no contexto social, econômico e até mesmo político. O consumidor, que antes era parte significativa do objetivo final do processo mercadológico, o chamado "comprador", passou a ter papel de protagonista no processo, ao ser "ouvido" e questionado sobre suas necessidades e desejos de consumo.

Essas tendências têm como objetivo entender de forma mais completa o pensamento, os desejos e as necessidades dos consumidores, assim como os modos pelos quais eles interpretam o que lhes é imposto pelo mercado em termos de consumo. O foco principal das atividades mercadológicas, nesse momento histórico, passou a ser a experiência do consumidor, de uma forma mais ampla, envolvendo não apenas as questões relacionadas à satisfação das necessidades, mas sim à satisfação do ser humano consumidor.

Diante da possibilidade de se abordar o consumidor como pessoa e entendendo que esse pode ser um percurso que oferece um novo posicionamento para a área, surgiu essa pesquisa, a partir do desenvolvimento dos estudos de marketing e da contribuição de outras abordagens e teorias, além da psicológica, que contribuíram para ampliação dos estudos sobre o conceito de consumidor no mundo contemporâneo.

Essa nova possibilidade de abordar o consumidor como pessoa na área do marketing, sugere um conhecimento mais aprofundado e claro sobre o que se entende como pessoa e também como esse conceito pode ser articulado à práxis do marketing. A proposta da experiência elementar, de Luigi Giussani (1922-2005), presente na obra $O$ senso religioso (2009), que foca a trajetória da experiência humana no impacto com a realidade, nos parece atender a essa demanda. Também, foi analisado o trabalho de Mahfoud (2012), na obra Experiência elementar em psicologia - aprendendo a reconhecer, que trabalha o conceito de Giussani, especificamente para a área da psicologia com a proposta de oferecer aos psicólogos uma nova forma de se relacionar com os seus pacientes. 
Ao escolher o método histórico, alguns conceitos centrais surgiram como: pessoa, experiência, experiência elementar e consumidor. Assim, observaram-se como os diferentes conceitos de consumidor influenciaram de forma decisiva a atividade mercadológica, culminando no uso atual desse conceito como "pessoa". Dessa forma, para essa investigação, procurou-se fundamentar esse estudo, primeiramente a partir de um entendimento claro e aprofundado do que se entende por pessoa e experiência, através da história dos conceitos de pessoa e experiência. Posteriormente foi analisada a abordagem da experiência elementar, e como ela pode se relacionar com a definição do conceito de consumidor, segundo as novas tendências do marketing contemporâneo.

\section{O conceito de pessoa e o desafio do homem moderno}

O limiar do século XX configurou-se como um período de grandes mudanças para a sociedade moderna nos campos da política, da cultura, da economia e dos relacionamentos humanos e celebrou um momento importante e decisivo para o avanço da civilização.

Os "tempos modernos" inauguraram, também, um processo de desarticulação da mentalidade medieval unitária (Giussani, 2004 apud Gaspar e Mahfoud, 2006) refletindo a ansiedade e a necessidade do homem de libertar-se de modelos anteriores e de se posicionar frente aos desafios que se apresentavam de forma mais incisiva. "O centro do universo, antes atribuído ao divino, tornou-se o próprio homem que, voltado para si mesmo, considera o sucesso em sua dimensão específica da existência e seu ideal de vida" (Giussani, 2004 apud Gaspar e Mahfoud, 2006: 4).

Essa ruptura com o pensamento medieval e as contradições que permeavam o dia a dia das pessoas, os questionamentos sobre a existência e a relação com o mundo e a natureza foram temas de análise de pensadores e filósofos, que se dedicaram a discutir e a criticar essa nova forma de se relacionar com a vida.

Um desses pensadores foi Romano Guardini (1885-1968), filósofo e educador que dedicou parte de sua vida ao trabalho acadêmico e ao processo de formação de jovens na Alemanha. Guardini contribuiu, através de suas obras, para a interpretação crítica dessa nova mentalidade que se formava e as consequências que poderiam se instaurar a partir das reduções do pensamento moderno.

Brandão (2005: 21) ao analisar uma das obras desse autor, O fim dos tempos modernos afirmou sobre a mudança de mentalidade do homem na modernidade: "O indivíduo torna-se importante por si mesmo, sem qualquer referência exterior ou transcendente, contrapondo-se à Idade Média, para a qual o divino era o elemento primeiro, que fundamentava a concepção que o homem tinha de si e do mundo".

Ao assumir essa posição mais centrada em si mesmo, o homem, passou a vislumbrar novas responsabilidades tornando-se "importante para si próprio, para os 
outros homens, e para a época inteira" (Guardini, 1963: 19). O conceito de pessoa (denominada nesse período como sujeito) no mundo moderno entrou em conflito e oposição com as ideias medievais.

Esse pensamento despertou responsabilidades e desafios que mudaram de certa forma, o modo de convivência e os relacionamentos humanos. A concepção de homem, de cultura e de valores entrou em choque com os pensamentos anteriores, lançando o ser humano numa busca incessante por novas formas de convivência que enfrentassem essa nova realidade.

Essas discussões também foram os temas centrais de outra obra do filósofo, intitulada $O$ mundo e a pessoa ${ }^{2}$. Trata-se de um conjunto de ensaios filosóficos sobre a essência do homem e sua relação com a natureza e o mundo. Em seu prefácio, Guardini (1963: 9) explicou que os três ensaios - a Pessoa, o Mundo e a Providência estavam unidos por uma análise sobre a forma como estava sendo conduzida a vida humana.

Em síntese, Guardini apontou em seus trabalhos o avanço e as conquistas da humanidade nos tempos modernos, os progressos gerados pelo rigor da ciência, pela "precisão técnica e pelo espírito caracteristicamente moderno de conquista, organização e elaboração do mundo". Mas, ao mesmo tempo, chamou a atenção para os riscos dessa nova mentalidade, que concebeu um sujeito autônomo, capaz de dominar e se tornar uma espécie de "juiz de si mesmo", "atribuindo soberania à cultura, aos diversos ramos do saber (...)". A "história referendou a gravidade e a magnitude desse risco, confirmando com os fatos a ingenuidade desse otimismo moderno" (Brandão, 2005: 26).

A sociedade contemporânea capitalista se consolidou nesse momento de desconstrução do passado medieval, criando possibilidades para o futuro, pautando-se na satisfação das necessidades no presente. O "homem das massas", segundo Guardini (2000: 55 apud Brandão, 2006: 7) foi "levado a abrir mão de sua originalidade e responsabilidade no modo de conduzir a vida, aceitando o que lhe é proposto ou imposto exteriormente". "Essa atitude é fruto da normatização de comportamentos, verificada quando se reduz o homem a um mero número, passível de ser manipulado e conduzido à mercê dos interesses de quem está no poder" (Brandão, 2006: 6). No contexto das massas e das sociedades contemporâneas, os indivíduos perdem as suas características pessoais e passam a ser parte de um universo mais amplo com características e necessidades mais padronizadas.

As pessoas passaram a conviver com uma crise de valores, sobretudo humanos. O grande paradigma desse momento é que apesar da humanidade ter alcançado um avanço significativo em todos os setores e atividades relacionados à sua existência, o uso da razão, antes porta-voz das grandes descobertas do século XX, passou a ter um papel coadjuvante na construção da sociedade pós-moderna. A racionalidade do homem ficou presa mais à necessidade de tornar os relacionamentos humanos consequências de padrões de comportamento ditados pelas regras de mercado.

110 ALCEU - n.33 - jul./dez. 2016 
A experiência do homem, na sociedade de consumo, retomada a partir da reflexão de Guardini (1963) e, na perspectiva da sociedade moderna, sofreu com essa desvalorização das exigências elementares de liberdade, de justiça, de beleza e de verdade, próprias do dinamismo humano nos relacionamentos diários.

A cultura, como manifestação do ser humano, também sofreu com o avanço da civilização que destruiu e corrompeu a história e a memória das pessoas na modernidade. Essa cultura dominante parece "ignorar" as exigências elementares do ser humano, tentando incutir uma forma de sociedade pautada em padrões de comportamento e de consumo.

\section{O conceito de experiência e sua relação com a psicologia}

Outro conceito importante que se articula com os temas centrais desse estudo é o conceito de experiência. Esse conceito, na atualidade, passa também, por uma mudança de sentido, na medida em que é usado apenas para relatar experimentos, contatos e atividades diárias. $\mathrm{O}$ conceito de experiência foi retomado nesse estudo no contexto da história das ciências e sua apropriação pela psicologia científica.

As definições de "experiência" têm raízes históricas e sofreram, na cultura ocidental, "uma incontrolável deteriorização semântica", descaracterizando a sua fundamentação filosófica e simplificando o seu uso apenas como parte de um conteúdo emocional, "o que reduz a um nível naturalista e imediatista, eliminando o sujeito ativo do processo" (Gaspar e Mahfoud, 2006: 2).

Molioni (1992, apud Massimi e Mahfoud, 2007: 27) explica que "no contexto hodierno, encontram-se algumas reduções da concepção de experiência que por sua vez fundamentam-se em alicerces teóricos propostos pelas filosofias modernas e contemporâneas".

Por diferentes autores, a experiência é reduzida a um significado emocional como algo que se adverte imediatamente e de modo espontâneo (Massimi e Mahfoud, 2007). Em outras situações, a experiência é concebida como "experimentalismo", como um experimento científico em que "provar" significa comprovar a sua existência. Os mesmos autores afirmam que, nesse sentido, "o real identifica-se com o que é passível de ser testado pela experimentação, não podendo ser aí incluídos valores ou relacionamentos pessoais (a menos que o sujeito se submeta a eles), de modo que a experiência é tomada como um "provar" sem razões"( Massimi e Mahfoud, 2007: 17).

Ao retomar esse conceito numa dimensão histórica, compreende-se a importância de seu entendimento, principalmente para autores como W. Wundt (1900) e W. James (1989), que "utilizaram conceitos de experiência baseados na filosofia empirista e nos postulados das ciências naturais" (Massimi e Mahfoud, 2007: 17), e fundamentaram os pressupostos da ciência da psicologia moderna. Para a análise do conceito de experiência segundo essa dimensão histórica e para realizar tal percurso 
histórico, foram utilizados os trabalhos de Massimi e Mahfoud (2007), Mahfoud e Massimi (2008), e Gaspar e Mahfoud (2006).

$\mathrm{Na}$ constituição da história dos saberes psicológicos ${ }^{4}$, o tema da "experiência" foi essencial para se compreender os elementos fundamentais da natureza humana. Aristóteles (384 a.C./322 a.C.) discutiu essa temática como sendo uma necessidade humana para aquisição do conhecimento. Massimi e Mahfoud (2007) retomaram a abordagem do filósofo ao analisarem o primeiro capítulo do primeiro livro da obra Metafísica (Aristóteles, século IV a. C./1969, apud Massimi e Mahfoud, 2007): "A experiência é uma etapa da aquisição do conhecimento: várias lembranças de uma mesma coisa chegam a constituir a experiência, independentemente de sua veracidade que poderia vir a ser verificada pelo intelecto" (Massimi e Mahfoud, 2007: 17). É a partir da experiência que se obtém o conhecimento. "Com efeito, a experiência serve ao homem para atestar que certo fato ocorreu, mas não para definir o motivo de seu acontecer" (Massimi e Mahfoud, 2007: 18).

Na Idade Média, o pensamento estava moldado por uma "mentalidade unitária" do real, a partir da consolidação de significados relacionados a Deus. A base do conhecimento era a sustentação da fé cristã, e a partir desse suporte teológico é que o homem tinha a capacidade de vivenciar as suas experiências.

Na obra de Santo Agostinho (386/ 1998), Solilóquios ${ }^{5}$ o ponto de partida para a revelação da experiência e o "conhecimento sensorial" estava atrelado a uma complexa relação com Deus. No tratado $A$ Trindade (399-422/2000, livro IV, capítulo 20, apud Massimi e Mahfoud, 2007: 19), por exemplo, Agostinho, seguindo a tradição medieval revelou o conceito de experiência em relação a Deus e o classificou como "verbo de Deus". O verbo, nesse sentido, significava "conhecimento experiencial (no sentido de "ciência saborosa, ou seja, de um entendimento que envolve também a sensação e o afeto")". Para Tomás de Aquino (1225-1274), seguindo a tradição de Agostinho, o "conhecimento experiencial de Deus, afirmando que se tratava de um "conhecimento saboroso" (Suma, I, qu. 43, 5,3, apud Massimi e Mahfoud, 2007: 20), guiado pelo amor". O autor ampliou esse pensamento, incluindo não só os sentidos externos ligados aos órgãos sensoriais, mas também, aos "quatro sentidos internos: fantasia, cogitativa, memória e senso comum". ${ }^{6}$

$\mathrm{O}$ avanço das ciências, a necessidade de se conquistar um maior bem-estar para a sociedade contribuiu para o avanço da valorização da razão humana. Nesse contexto surgiram os autores precursores da ciência moderna, como Galileu, Hobbes e Descartes.

O termo "experiência" para Massimi e Mahfoud (2007: 23) passou a "designar a concepção do real que o homem elaborava através dos métodos de conhecimento escolhidos para tanto, dentre os quais, o mais fidedigno é o conhecimento científico".

O filósofo inglês David Hume (1711-1776), seguidor do pensamento empirista, propôs examinar a experiência com "espírito de exatidão e do raciocínio"

\section{$1 / 2$ ALCEU - n.33 - jul./dez. 2016}


(1972: 13 apud Massimi e Mahfoud, 2007: 23). Segundo Hume: “(...) a existência de qualquer ser somente pode ser provada mediante argumentos derivados de sua causa ou de seu efeito, e estes argumentos se fundam inteiramente na experiência" (1972: 13 apud Massimi e Mahfoud, 2007: 23).

A posição de Hume expressava a cisão filosófica do movimento empirista. Posteriormente, segundo a filosofia positivista de A. Comte e H. Spencer, “(...) a ciência é o único saber que permite apreender a experiência de modo unificado" (Massimi e Mahfoud, 2007: 23).

Os movimentos científicos fomentaram os estudos de diferentes áreas do conhecimento e, nesse contexto, surgiu a psicologia moderna, como uma área que definitivamente se separava da tradição filosófica e da fisiologia. Os processos psicológicos passaram a ser medidos e testados em laboratórios a partir dos pressupostos empiristas e positivistas. Os autores que se destacaram nesse período foram Wundt (considerado o pai da psicologia moderna) e James, nas universidades da Alemanha e dos Estados Unidos, respectivamente.

Wundt propõe a unidade metodológica entre ciências naturais e psicologia, de modo que os métodos da psicologia experimental possam ser concebidos como análogos aos das ciências naturais. O mesmo valeria para as ciências do espírito. A psicologia - como ciência da experiência imediata - é a ciência empírica, reintegrando as ciências naturais ao seu contexto originário dado antes das operações de abstração. (...) Em suma, no processo de fundação da psicologia moderna, a concepção wundtiana de experiência elimina de sua gênese a relação entre sujeito e objeto do conhecimento procurando superar a visão da psicologia filosófica tradicional em que a relação sujeito objeto acarreta a presença do sujeito ativo na elaboração da experiência (processada pelas suas potências psíquicas a partir da simples recepção da sensação pelo mundo externo) (Massimi e Mahfoud, 2007: 25).

Ao assumir esse caráter experimental e científico, a partir da instauração da psicologia moderna, as demais abordagens psicológicas, que floresceram no início do século XX, foram influenciadas em sua concepção e fundamentação, o que provocou uma "postura reducionista" na forma de conceber o ser humano no contexto das ciências psicológicas e comportamentais.

Ainda nesse percurso histórico, as contribuições da fenomenologia ${ }^{7}$ para a discussão do conceito de experiência na psicologia contemporânea foram fundamentais para o resgate da dimensão da subjetividade do conceito. O valor da experiência foi redescoberto pela fenomenologia "na qual se identifica tanto um nível passivo do sujeito que sofre impacto da presença no mundo, quanto um nível caracterizado pela presença ativa do sujeito, que elabora tal impacto buscando apreender a presença no mundo" (Gaspar e Mahfoud, 2006: 6). 
Husserl, em sua obra Crise das ciências europeias e a fenomenologia transcendental (1954/2002), criticou a psicologia moderna, e considerou que ela fracassou, pois não realizou a indagação acerca da subjetividade concreta e plena “(...) a reflexão radical e livre de preconceitos, que abriria necessariamente à dimensão transcendental subjetiva" (Husserl, 2002: 235, apud Mahfoud e Massimi, 2008: 57).

$\mathrm{O}$ reconhecimento de que algo deveria ser superado pelas abordagens científicas da psicologia e das ciências do comportamento humano, permeou a obra de Husserl e de outros fenomenólogos, discípulos desse autor como a filósofa Edith Stein (1891-1942). Na experiência, na vivência, no dia a dia das pessoas são encontradas "realidades mistas", que exigem do psicólogo diferentes modalidades de abordagem e o reconhecimento da subjetividade que permeia o sentido atribuído ao conceito de experiência.

O conceito de experiência fundamentado na fenomenologia de Husserl contribuiu para uma nova forma de abordar e retomar a subjetividade humana e o mundo real.

Avançando nos estudos sobre experiência, o método fenomenológico de Husserl ofereceu subsídios para diferentes áreas influenciando, de certa forma, diferentes autores e estudiosos, que conduziram seus estudos para a busca de uma interpretação do pensamento fenomenológico afirmando a necessidade de "(...) deixar falar a experiência elementar do homem (...)".

Nesse contexto, coloca-se a contribuição de Luigi Giussani, teólogo, filósofo e educador, ao propor o conceito de experiência elementar na obra $O$ senso religioso, publicada originalmente em 1997, sendo o primeiro livro da trilogia O percurso. A obra, considerada pelo próprio autor como um "método" para o conhecimento de si e dos outros, motiva o leitor a redescobrir, a partir de suas exigências elementares, a sua estrutura originária como ser humano, inserida no contexto de sua própria realidade.

\section{Experiência elementar e psicologia}

A abordagem da experiência elementar apresentada na obra de Giussani (2009) analisa com profundidade a trajetória da realização humana e procura compreender o ser humano de uma forma mais completa. O contato com a realidade é entendido em termos de: atividades de trabalho diário, relacionamentos, vida em comunidade, estímulos externos, enfim, tudo o que motiva e solicita as pessoas ao convívio com os outros e consigo mesmas. A partir dessas experiências, surgem os relacionamentos, contatos, e questionamentos que as pessoas vivenciam, e que estão presentes na atividade humana.

$\mathrm{O}$ autor define a experiência elementar como "um conjunto de exigências e evidências com as quais o homem é lançado no confronto com tudo o que existe" (Giussani, 2009: 24). Todo ser humano carrega em si exigências constitutivas de 
verdade, de justiça, de beleza, de amor, entre outras. São exigências próprias do homem que, ao longo da vida, são sedimentadas pelo convívio com as tradições familiares, da sociedade, da moda, da história e da memória. Elas se manifestam a partir do contato com a realidade que o cerca e que o estimula e motiva. As evidências se apresentam como o que está "diante dos olhos". O mundo e a realidade a nossa volta existem além da nossa presença física, ou seja, a realidade emerge em nossos contatos diários (Justo e Massimi, 2014: 124).

A palavra elementar, nessa proposta, também se relaciona com original, único e primeiro. Assim, todas as experiências verdadeiramente humanas e de personalidade passam "pelo crivo de uma "experiência original" primordial que constitui o ser humano ao se confrontar com a realidade das coisas" (Giussani, 2009: 16). Nas palavras de seu autor, experiência elementar é definida como:

(...) um conjunto de exigências e evidências com as quais o homem é lançado no confronto com tudo o que existe. (...) A elas podem ser dados muitos nomes, através de diversas expressões, como: exigência de felicidade, exigência de verdade, exigência de justiça, etc. Seja como for, são como uma centelha que põe em ação o motor humano; antes delas não ocorre nenhum movimento, nenhuma dinâmica humana. Qualquer afirmação de uma pessoa, desde a mais banal e quotidiana até a mais ponderada e plena de consequências, só pode ser feita tendo por base esse núcleo de evidências e exigências (Giussani, 2009: 16).

A experiência a que Giussani se refere, emerge na consciência da pessoa quando esta busca respostas para as suas exigências fundamentais, nos momentos de dor, de alegria, de depressão, de excesso de trabalho e de dificuldades para lidar com as questões práticas do cotidiano, de reflexão, etc.

A experiência elementar representa o "núcleo mais profundo da identidade pessoal e, exatamente por isso, se torna o crivo crítico com o qual cada pessoa se aproxima da realidade para avaliá-la" (Giussani, 2009: 16). Ela se evidencia através do percurso do conhecimento descrito por Giussani, nos primeiros capítulos de seu livro, como a tríplice premissa: realismo, razoabilidade e incidência da moralidade. Por meio destas três premissas, Giussani sugere um caminho de aberturas para o encontro com o verdadeiro ser humano e de como ele, através de suas experiências, reage diante das realidades que lhe são impostas.

Por realismo, o autor explica que se deve "observar um objeto de modo tal que ele seja conhecido, o método não deve ser imaginado, pensado, organizado ou criado pelo sujeito, mas imposto pelo próprio objeto" (Giussani, 2009: 21).

Aquilo que "é tomado fora de nós" corresponde às informações que recebemos do nosso contato com a realidade, com o dia a dia, com o que é evidenciado pela moda, pela mídia, etc. Se tivermos uma determinada informação externa, por exemplo, e não 
conseguimos processar internamente, questionando e analisando se aquele objeto ou acontecimento realmente "me corresponde", então é como se estivéssemos "alienados" diante de tal fato. Por outro lado, se esse juízo é dado por algo interno, imanente, deixa de ser alienante e passa a ser uma experiência original, a partir de algo que nos corresponde. Portanto, ao observar, por exemplo, um aparelho celular ou uma boneca, estes possuem características diferentes e se apresentam de forma diversa. É evidente que esses objetos são criados fora das pessoas, e nas experiências humanas diárias, esses objetos já se tornaram conhecidos. Nas palavras do autor: "Aquilo que cria o objeto é o nosso conhecimento, é o espírito e a energia do homem. Tanto é verdade que se o homem não o conhecesse seria como se não existisse" (Giussani, 2009: 25).

Após ter contato e conhecer o objeto, o que para Giussani é "apenas o início do conhecimento", parte-se para a formulação de um juízo, uma avaliação desse objeto. A palavra experiência não significa apenas "provar": o homem experiente não é aquele que acumula "experiências - fatos e sensações - a torto e a direito. Semelhante acúmulo indiscriminado gera frequentemente, destruição e esvaziamento da personalidade" (Giussani, 2009: 23). Segundo o autor, experiência coincide com o "provar", mas, sobretudo com o "juízo dado a respeito daquilo que se prova". A pessoa é, antes de tudo, consciência. Por isso, o que caracteriza a experiência não é tanto o fazer, o estabelecer relações com a realidade como fato mecânico; "(...) o que caracteriza a experiência é compreender uma coisa, descobrir-lhe o sentido" (Giussani, 2009: 23). A experiência, nesse sentido, implica em descobrir o sentido das coisas, ou, usando um termo de Giussani, em dar um "juízo" acerca do fato ou experiência realizada. O crivo para formular este juízo é dado pela experiência elementar.

A segunda premissa de Giussani é sobre a razoabilidade. Nela, o sujeito aparece em primeiro plano, pois é ele que age a partir do real que se apresenta. Comparada com a primeira premissa, Giussani (2009: 31) afirma:

Pela primeira premissa - necessidade de realismo - viu-se prevalecer o objeto; com efeito, o método com o qual se enfrenta qualquer coisa é determinado pelo objeto, e não imaginado caprichosamente pelo sujeito. A segunda premissa, por sua vez, coloca em primeiro plano o sujeito que age: o homem.

A razoabilidade é um "modo de agir que exprime e realiza a razão". A razão, para Giussani (2009: 31) "é a capacidade de dar-se conta do real segundo a totalidade dos fatores". Ao tomar contato com o real, o uso da razão provoca "aberturas" para se relacionar com o objeto.

O autor enfatiza que se deve partir da distinção: "como percebemos que uma atitude é ou não razoável?” (Giussani, 2009: 43). A partir da nossa relação cognitiva com o real desenvolve-se um método de observação crítica dos fatores que nos correspondem enquanto pessoas. Tomamos um exemplo de Giussani (2009: 32): 
Por exemplo, se um amigo nosso aparecesse vestido como um cavaleiro medieval, com elmo e armadura, numa época do ano bem longe do Carnaval, e, às nossas espantadas perguntas, respondesse seriamente não ter a certeza de que alguém entre os presentes não nutrisse intenções agressivas contra ele e que, consequentemente, achara oportuno precaver-se dessa eventualidade, sentir-nos-íamos diante de uma anormalidade: a atitude do nosso amigo certamente não seria considerada razoável.

No exemplo, a atitude da pessoa que aparece vestida de cavaleiro parece ser não razoável diante da "totalidade dos fatores". Parece ser uma atitude inadequada. Só será adequada se a pessoa estiver se preparando, por exemplo, para participar de uma cena numa peça de teatro.

Giussani também nos alerta para o uso reduzido da razão, isto é, "não limitar o âmbito da razoabilidade". Nesse ponto, o autor indica dois argumentos (Giussani, 2009: 33):

a) Muitas vezes o racional não é identificado como o "demonstrável", no sentido estrito do termo; b) O razoável tampouco se identifica com o "lógico". A lógica é um ideal de coerência: estabeleçamos certas premissas (como hipóteses), desenvolvamo-las coerentemente e teremos uma "lógica". Se as premissas forem erradas, a lógica perfeita dará um resultado errado.

Para o primeiro argumento podemos destacar, por exemplo, o amor de um pai com relação a um filho. Às vezes não é "demonstrável" e nem por isso deixa de ser razoável. Sobre o segundo argumento - o que "é razoável tampouco se identifica como lógico", podemos observar, por exemplo, quando um jovem, apesar das adversidades do contexto em que está inserido, se destaca dos demais. A lógica seria que o ambiente no qual esse jovem estivesse inserido, deveria ser determinante para seu futuro. Porém essa "lógica" nem sempre se cumpre. O desenvolvimento de um jovem é possível, mesmo em condições precárias, desde que suas atitudes sejam razoáveis, adequadas ao que ele espera e almeja.

A terceira premissa é definida como a incidência da moralidade sobre a dinâmica do conhecimento. Nesse sentido, a palavra moralidade, que vem de moral e se apresenta como um "conjunto de regras de conduta consideradas como válidas" ${ }^{10}$ pode variar de acordo com a dinâmica da pessoa durante uma determinada experiência. Para essa conclusão, observa-se que o homem não é só o uso da razão inseparável da unidade da pessoa. Assim, Giussani (2009: 46) estabelece que "a razão é imanente a toda unidade do nosso eu, está organicamente relacionada; por isso, diante de uma dor física, de uma raiva, de uma decepção pela incompreensão dos outros, não se usa bem a razão". O uso da razão diante de um acontecimento parte de uma experiência pessoal a partir 
de algo que a comove. Essa comoção não está dissociada de uma unidade profunda que o ser humano possui entre corpo, mente e espírito.

Realismo, razoabilidade e incidência da moralidade sobre a dinâmica do conhecimento definem o método de conhecimento para se abordar o conceito de experiência elementar, usado por Giussani.

Com efeito, para reconhecer o sentido mais amplo de experiência, aquela a que se refere Giussani, no contexto das atividades diárias, não basta apenas a observação, mas sim "(...) aprender a reconhecer o essencial em seu dinamismo característico (...)" (Mahfoud, 2012: 30). O psicólogo enfatiza que para reconhecer a experiência em suas atividades diárias deve-se "(...) aprender a reconhecer que somos exigência de felicidade, exigência de realização, de conhecimento, por exemplo, não como um setor isolado da vida, mas como expressão de uma exigência fundamental do nosso ser (...)" (Mahfoud, 2012: 30).

A experiência a que se refere Giussani permite analisar a presença do humano nos relacionamentos diários de uma forma "totalizante". Mahfoud reforça que a análise do sujeito passa pelas influências que ele carrega ao longo de sua trajetória, seja no contexto do local onde reside e foi criado, na sua história e contexto social, político e econômico. O berço familiar representa, também, um forte elo com a sua essência, a construção de seus valores, personalidade e exigências.

Em contraposição à crise e questionamentos sobre o conceito de homem da cultura contemporânea, Mahfoud (2012: 35) nos alerta que o tema da experiência elementar retoma a nossa atenção “(...) redimensionando a centralidade do sujeito nos processos sociais e históricos e em toda ação concreta - esta vista como tomada de posição social (...)".

A relação do sujeito passa por uma relação consigo mesmo, com o próximo, com a cultura e com a história num sentido mais amplo. Para diferentes áreas do conhecimento, que trabalham com a presença humana como centro de suas atividades, pode representar uma tomada de posicionamento voltada para a construção de relacionamentos mais densos e duradouros. Um exemplo é a própria psicologia, conforme exemplifica Mahfoud (2012:35): "Para a psicologia se abre um importante campo de revisão dos conceitos de pessoa e experiência, permitindo inclusive uma releitura da história cultural quanto às compreensões dos processos de percepção de si mesmo característicos de cada cultura ou momento histórico". A possibilidade de utilização do conceito de experiência elementar para a psicologia amplia o conceito de experiência para essa área e retoma o valor da experiência enquanto ligada ao conhecimento vivenciada na atividade diária, abandonado pela filosofia da modernidade. $\mathrm{Na}$ área específica do marketing, o conceito de experiência elementar pode ser utilizado como uma possibilidade de abordagem do consumidor enquanto pessoa, e como centro das decisões mercadológicas. Analisar o consumidor enquanto pessoa significa repensar práticas de mercado já consolidadas pela área que tentam

\footnotetext{
$1 / 8$ ALCEU - n.33 - jul./dez. 2016
} 
manipular necessidades e desejos e, ao contrário, imaginar e criar formas que evitem abordá-lo apenas com o objetivo final de levá-lo ao consumo, mas criando uma espécie de sintonia com a sua própria vontade.

\section{Psicologia, marketing e experiência elementar: implicações para conceito de consumidor}

O conceito de consumidor no marketing contemporâneo pode ter sido influenciado pela aproximação entre as áreas de marketing e psicologia, sobretudo a partir das pesquisas experimentais que contribuíram para os estudos de psicologia e comportamento do consumidor. Porém, diante das mudanças no comportamento do consumidor, que tem se tornado mais "crítico e ativo" frente às abordagens de mercado, que "induzem" o consumo de diferentes produtos e serviços, a área de marketing tem direcionado seus esforços para relacionar-se com os diferentes públicos de uma forma mais "humana".

Esses esforços favorecem o surgimento de ações que contribuem para intensificar um contato mais próximo com o consumidor final, a partir da utilização, por exemplo, de estratégias voltadas ao engajamento com a marca. As estratégias mercadológicas, segundo essa perspectiva, se tornam mais próximas do consumidor, na divulgação e desenvolvimento da marca e do produto.

No caso específico da área de marketing e das relações de consumo, este foi utilizado no final dos anos 1990, para se referir aos termos "experiências de consumo" ou "experiências com a marca". A ideia de experiência nesse contexto remetia a "acontecimentos individuais que ocorrem como resposta a algum estímulo" (Schmitt, 1999: 74). De acordo com esse autor, os profissionais de marketing deveriam "apontar o ambiente e o cenário certos para que as experiências pelas quais o cliente queira passar possam acontecer” (Schmitt, 1999: 75).

Para conceituar a ideia de "experiências de consumo" como parte das estratégias e práticas de marketing, Schmitt (1999) partiu da análise de fatores neurobiológicos, psicológicos e comportamentais dos consumidores. "A ideia de que existem áreas funcionais distintas do cérebro, que correspondem a experiências distintas, foi chamada de visão modular da mente" (Schmitt, 1999: 76).

Os profissionais de marketing oferecem "estímulos" para a compra e a propagação de diferentes ideias, produtos e serviços. Esse estímulo é induzido na medida em que "oferece as experiências que os consumidores mais esperam e desejam". Isso não é por acaso, mas sim resultado das pesquisas de mercado e comportamento dos consumidores.

Um exemplo dessa prática pode ser observado nas estratégias para desenvolvimento de novos produtos, como parte da atividade de marketing. A escolha do nome, da logomarca e do design dos produtos pode iniciar um processo de expe- 
riência de consumo. A comunicação através da campanha publicitária se encarrega de intensificar e marcar esses apelos, levando os consumidores a experimentarem o produto. Além da ênfase no design, outros fatores como: a ambientação das lojas, o patrocínio a eventos culturais e esportivos, a comunicação através do meio virtual e as pessoas envolvidas nas estratégias mercadológicas, como vendedores, representantes das empresas, prestadores de serviço e qualquer outra pessoa que tenha ligação com a empresa e a marca, podem ser classificados como "provedores de experiência".

Essa forma de conceber o conceito de experiência, na área de marketing, se assemelha, num certo sentido, ao conceito empirista de experiência, em que o sujeito se torna passivo diante dos estímulos. Essa visão, como vimos, estava presente no conceito de experiência protagonizado pelos fundadores da psicologia moderna.

Dessa forma o conceito de experiência elementar, a partir de Giussani (2009), pode ser útil para a psicologia e outras áreas, como o marketing, por exemplo, na medida em que abre a discussão para a retomada do $e u$ no contexto das atividades diárias.

\section{Considerações finais}

Através desse estudo, evidenciou-se que o conceito de consumidor, em diferentes épocas e contextos históricos, recebeu uma contribuição significativa dos estudos teóricos e experimentais de psicólogos, que passaram a estudar a psicologia e a sua aplicabilidade na publicidade. A aproximação entre as áreas foi "quase" perfeita, no sentido de que, ao reconhecerem a importância de desvendar o comportamento do consumidor através do auxílio, das pesquisas psicológicas relacionadas a comportamento, consumo, hábitos e atitudes, tornaram a atividade de marketing um forte aliado da emergente economia capitalista norte-americana.

No final da década de 1980, as novas tendências da área de marketing começaram a evidenciar novas possibilidades de se conceituar o consumidor, a partir de uma necessidade de se reconhecer a pessoa presente nas atividades de consumo. Essa necessidade emerge frente às exigências impostas pelo mercado e pelo próprio consumidor, que se tornou mais crítico e participativo. Essa nova proposta se tornou uma possibilidade importante e necessária aos estudos sobre mercado, frente às novas realidades que as populações dos países capitalistas enfrentam, decorrentes da distribuição desigual de rendas, da ênfase ao consumo e ao consumismo, assim como da degradação do meio ambiente fruto do avanço das tecnologias e da informação.

A resposta da área de marketing frente às novas tendências tem gerado práticas de mercado mais focadas na perspectiva da pessoa presente no consumidor. Alguns exemplos vêm de empresas que organizam campanhas educativas para redução do consumo de álcool, de drogas, de combate à fome, de erradicação da pobreza, e de apoio a causas ambientais, enfatizando a importância da relação "eu" consumidor com os desafios da humanidade. Porém, em muitos casos, ainda existe uma forte 
tendência de se criar campanhas com essas temáticas apenas pensando em resultados de imagem da empresa, sem preocupação com o impacto que a geração desse tipo de conteúdo pode oferecer ao consumidor.

O conceito de pessoa evidenciou-se nessas áreas, a partir do reconhecimento de que o ser humano considerado como "centro" das abordagens e atividades dessas áreas, pode representar uma escolha importante e necessária para as discussões que envolvem os temas relacionados à vida psíquica, ao cotidiano e ao contato com a realidade no dia a dia profissional e pessoal.

A conclusão desse estudo levanta a hipótese de que a experiência elementar, como uma abordagem antropológica filosófica, pode ser pertinente para se discutir o conceito de consumidor no mundo contemporâneo, a partir dos novos estudos de marketing que trabalham uma perspectiva mais humana para essa atividade. E ainda, tais práticas, podem auxiliar nos estudos e atividades relacionadas à psicologia e ao comportamento do consumidor, pois já são utilizadas por profissionais psicólogos como um método de trabalho clínico e terapêutico. ${ }^{11} \mathrm{~A}$ abordagem da experiência elementar no contexto da formação acadêmica e profissional dos graduandos em marketing e comunicação poderia ser utilizada como uma forma de contribuição dada pelas ciências humanas, colaborando para o desenvolvimento do espírito crítico desses profissionais, apesar das imposições do mercado, que direcionam as atividades de marketing e comunicação para contemplarem as expectativas de crescimento e aumento do consumo em suas estratégias para diferentes tipos de público consumidor. Não se trata, evidentemente, de criar uma nova abordagem de marketing, a partir dos estudos da experiência elementar.

Outra contribuição diz respeito à ampliação desses estudos para as áreas da psicologia, do marketing e da comunicação, e ainda, para a formação de profissionais dessas áreas, que trabalham de forma interdisciplinar, com questões sobre o ser humano e sua relação com as práticas de consumo.

Carmen Silvia Porto Brunialti Justo Professora do Centro Universitário Moura Lacerda (CUML - Ribeirão Preto) carmen@justo.com.br/pp@mouralacerda.edu.br

Marina Massimi

Professora da Universidade São Paulo (USP - Ribeirão Preto) mmassimi3@yahoo.com

Recebido em setembro de 2015.

Aceito em janeiro de 2016. 


\section{Notas}

1. Esse artigo é parte da dissertação de mestrado defendida na Faculdade de Filosofia, Ciências e Letras de Ribeirão Preto. O trabalho está disponível em: http://www. teses.usp.br/teses/disponiveis/59/59137/tde-15122014-155052/pt-br.php. Esse trabalho foi apresentado no 47th Annual Meeting of Cheiron: The International Society for the History of Behavioral \& Social Sciences, no mês de junho de 2015, na University of Kansas - KS, USA.

2. Do original alemão Welt und Person (1939). Para esse trabalho utilizamos a tradução brasileira de 1963, com o título O mundo e a pessoa - Ensaio para uma doutrina cristã do homem.

3. Lima Vaz (2000 apud Gaspar e Mahfoud, 2006).

4. "Sob o rótulo de História da Psicologia compreendem-se dois domínios distintos, o da história dos saberes psicológicos e o da história da psicologia científica: o primeiro utiliza-se dos métodos próprios da história cultural e da história social, o segundo assume as modalidades de investigação sugeridas pela historiografia das ciências" (Massimi, 2010: 100).

5. Apud Massimi e Mahfoud, 2007, p. 18.

6. Ibidem em Massimi e Mahfoud, 2007 e retomados por Gaspar e Mahfoud, 2006.

7. O pensamento de Edmund Husserl (1859-1938) deu origem a uma das mais férteis correntes da filosofia moderna, a fenomenologia. Essa corrente influenciou decisivamente o movimento filosófico e cultural que se propagou na Europa após o fim da Segunda Guerra Mundial, conhecido como existencialismo. Fenomenologia e existencialismo, em suas convergências, tensões e entrecruzamentos, constituem juntos uma das importantes matrizes filosóficas das psicologias do século XX. (JacóVilela; Ferreira; Portugal, 2007: 319).

8. Interpretação de Mahfoud e Massimi (2008: 59), a partir do trecho "a vida espiritual se apresenta como processo psíquico; tudo o que é psíquico nos aparece ligado com o ser material; as formações espirituais objetivas, por sua vez, nos aparecem como fundamentadas no ser da natureza. Por outro lado, todo ser natural pode se tornar portador de um sentido espiritual. Por isso não nos maravilhemos se nas ciências empíricas - orientadas para os objetos da experiência - se entrelaçam métodos diversos a serem diferenciados" (Stein, 1922/1999).

9. Citado por Mahfoud (2012: 17), o autor afirma que expoentes da filosofia da língua francesa, desde Ricoeur a Lévinas, a Marion moveram-se nessa direção.

10. Ferreira, Aurélio Buarque de Holanda. Novo Aurélio Século XXI: o dicionário da língua portuguesa. $3^{\text {a }}$. ed.- Rio de Janeiro: Nova Fronteira, 1999.

11. Mahfoud, M. Experiência elementar em psicologia. Aprendendo a reconhecer. Brasília: Editora Universa e Artesã Editora, 2012.

\section{Referências}

BRANDÃO, S.R. O método formativo de Alfonso López Quintás: Fundamentos filosóficos e experiência educativa. Tese de Doutorado. Faculdade de Educação da Universidade de São Paulo, 2005. 
BRANDÃO, S. R. A pessoa em Romano Guardini: um desafio à autonomia e desamparo do homem contemporâneo. Memorandum, 10, 147-156 2006. Disponível em WorldWideWeb:<http://www.fafich.ufmg.br/ memorandum/a10/branda01.htm. 134 acessado em 13 de março de 2013.

FERREIRA, Aurélio Buarque de Holanda. Novo Aurélio Século XXI: o dicionário da língua portuguesa. $3^{\text {a }}$. ed. Rio de Janeiro: Nova Fronteira, 1999.

GUARDINI, R. O encontro. In: COGO, L. e Chaves, C.C.C. (Orgs.) Curso de Extensão em Educação Infantil. Belo Horizonte: AVSI, 2002. p. 204-212.

. O mundo e a pessoa. Ensaio para uma doutrina cristã do homem. Trad. Fernando Gil. São Paulo: Livraria Duas Cidades, 1963.

GIUSSANI, L. Realidade e juventude: o desafio (trad. M. J. M. Mendes). Lisboa: Diel, 2003. In: MAHFOUD, M. Apresentação do curso Experiência elementar em Psicologia, 2012.

. O caminho para a verdade é uma Experiência. São Paulo: Edições Tenacitas, 2007. In: MAHFOUD, M. Apresentação do curso Experiência elementar em Psicologia, 2012. . O senso religioso. Brasília: Ed. Universa, 2009.

JUSTO, C. S. P. B. e MASSIMI. M. Psicologia, marketing e experiência elementar: implicações para o desenvolvimento do conceito de consumidor. Dissertação de Mestrado, apresentada à Faculdade de Filosofia, Ciências e Letras de Ribeirão Preto/USP, 2014.

KOTLER, P. Administração de Marketing. São Paulo: Prentice Hall, 2000.

KOTLER, P.; KARTAJAYA, H e SETIAWAN, I. Marketing 3.0 - As forças que estão definindo o novo marketing centrado no ser humano. Rio de Janeiro: Elsevier, 2010.

MAHFOUD, M. e MASSIMI, M. A pessoa como sujeito da experiência: contribuições da fenomenologia. Memorandum, 14, 52-61, 2008. Disponível em : WorldWideWeb: < http:// www.fafich.ufmg.br/ memorandum/a14/mahfoudmassimi02.htm acessado em 13 de março de 2013.

MAHFOUD, M. Experiência elementar em psicologia. Aprendendo a reconhecer. Brasília: Editora Universa e Artesã Editora, 2012. à alteridade, 2012 .

Material aula Curso: Experiência elementar em Psicologia: o eu e a abertura

. Métodos de Investigação em História da Psicologia. In: Psicologia em Pesquisa: UFJF. 4(02), p. 100-108. Julho-dezembro, 2010.

. (1998). A história das ideias psicológicas: uma viagem no tempo rumo aos

novos mundos. In: Diálogos Metodológicos sobre Prática de Pesquisa. Ribeirão Preto: Legis Summa, 1998.

MASSIMI, M.; PACHECO, P. R.; GONTIJO, S e PIMENTA, V. D. S. Apostila da Disciplina de Teorias e Sistemas I - Modelos de Ciência e Pesquisa em Psicologia: confronto entre diversas perspectivas. Ribeirão Preto, 2002.

MASSIMI, M. Psicologia e cultura numa perspectiva histórica. Temas em Psicologia, v.14, n. 2, 177-187, 2006.

MASSIMI, M. e MAHFOUD, M. A pessoa como sujeito da experiência: um percurso na história dos saberes psicológicos. Memorandum, 13, 16-31, 2007. Disponível em :WorldWideWeb:<http://www.fafich.ufmg.br/ memorandum/a13/mahfoudmassimi01. htm. retirado em 13 de março de 2013.

REICHHELD,F. O valor da fidelidade. In: JULIO, C. e NETO J.S. (Orgs). Marketing e vendas: autores e conceitos imprescindiveis. São Paulo: Publifolha, 2001.

TENÓRIO, F. G. (Org.). Responsabilidade social empresarial: teoria e prática. Rio de Janeiro: Ed. FGV, 2004. 


\section{Resumo}

As novas tendências do marketing contemporâneo sugerem a inserção do tema da pessoa no que diz respeito às abordagens mercadológicas do conceito de consumidor, mas sem uma fundamentação antropológica, filosófica e psicológica específica. $\mathrm{Na}$ busca por uma fundamentação que desse suporte a essa tendência e ampliasse a discussão, foi analisada a abordagem da experiência elementar de Luigi Giussani (2009). O objetivo dessa pesquisa é compreender as possíveis relações entre a psicologia, o marketing e a experiência elementar em relação ao tema do consumidor enquanto pessoa. Essa pesquisa situa-se no âmbito temático entre o marketing e a psicologia do consumidor, relacionando as áreas numa perspectiva histórica no período que compreende o final do século XIX e XX. A conclusão remete à ideia de que no século XXI existe uma possibilidade de se considerar o consumidor como "pessoa", e que a abordagem da experiência elementar pode ser pertinente para discutir essa aproximação.

\section{Palavras-chave}

História da psicologia. Experiência elementar e psicologia. História do marketing.

\section{Abstract}

Psychology, marketing and the elementary experience: implications to the development of the concept of consumer

Among the Contemporary Marketing, the notion of "person" seems to be the tonic for marketing approach of the concept of consumer, attempting to grasp a more human vision of the consume, despite lack any anthropological or philosophical foundation. Therefore, in search of a theorical foundation to these new trends, we have addressed to the "Elementary Experience by Luigi Giussani. So, this research aims to understand the possible relations between Psychology, Marketing and the Elementary Experience concept (Giussani, 2009) in order to develop an integral approach to the consumer seen as a person. It is a theoretical research that lies into the thematic scope between Consumer Psychology and Marketing, relating them in a historical perspective, in the period from the $19^{\text {th }}$ century to the $20^{\text {th }}$ century. The conclusion refers to the idea that the twenty-first century there is a possibility to consider the consumer as "person," and that the "Elementary Experience' may be relevant to discuss this approach.

\section{Keywords}

History of psychology. Elementary experience and psychology. History of marketing. 